\title{
La Zona Franca de Iquique y su impacto en el trabajo informal de mujeres migrantes fronterizas
}

\author{
Luz Icarte Ahumada \\ Universidad Arturo Prat, Iquique, Chile \\ Email: licarte@estudiantesunap.cl \\ Natalia Torres Torres \\ Universidad Arturo Prat, Iquique, Chile \\ Email: ntorrest@estudiantesunap.cl \\ Romina Ramos Rodríguez \\ Universidad Arturo Prat, Iquique, Chile \\ Email: romramos@unap.cl
}

\begin{abstract}
Resumen: La Zona Franca de Iquique ha sido un motor sostenido de desarrollo económico en la región de Tarapacá, al norte de Chile. Desde su creación, es un espacio de tránsito de bienes y personas que conecta a Tarapacá con el Centro Oeste Sudamericano. En términos geográficos este espacio resulta ser clave para la circulación debido a su posición fronteriza. Por ello es un atractivo nicho de empleo. ¿Cuáles son las condiciones de empleo que brinda a las mujeres migrantes? A partir de entrevistas realizadas a mujeres migrantes que trabajan en el barrio industrial de la Zona Franca se concluye que la oferta de empleo en este es de tipo precario y ofrece dificultades para realizar trámites administrativos que permitan a las mujeres regularizar su condición migratoria.
\end{abstract} Tarapacá

Palabras clave: Zona Franca, migraciones, feminización, empleo, región de

\section{The Free Trade Zone of Iquique and its impact on informal work of of border migrant women}

\begin{abstract}
The Free Trade Zone of Iquique has been a sustained engine of economic development in the Tarapacá region, in northern Chile. Since its creation, it has been a transit space for goods and people that connects Tarapacá with the West Central South America. In geographic terms, this space turns out to be key for circulation due to its border position. Therefore, it is an attractive niche for employment. What are the employment conditions that it provides to migrant women? From interviews conducted with migrant women working in the industrial
\end{abstract}


zone of the Free Trade Zone, it is concluded that the job offer in this area is precarious and offers difficulties to perform administrative procedures that allow women to regularize their migratory status.

Keyworks: Free Trade Zone, migration, feminization, employement, Tarapacá Region

\section{A Zona de Livre Comércio de Iquique e seu impacto no trabalho informal de mulheresmigrantes de fronteira}

Resumo: A Zona Franca de Iquique tem sido um motor sustentado de desenvolvimento econômico na região de Tarapacá, no norte do Chile. Desde sua criação, é um espaço de trânsito de mercadorias e pessoas que liga Tarapacá ao Centro Oeste Sul-Americano. Em termos geográficos, este espaço acaba por ser fundamental para a circulação devido à sua posição de fronteira. Portanto, é um nicho atraente para o emprego. Quaissão as condições de emprego que proporciona às mulheres migrantes? A partir de entrevistas realizadas com mulheres migrantes que trabalham na zona industrial da Zona Franca, conclui-se que a oferta de trabalho nessa área é precária e oferece dificuldades para a realização de procedimentos administrativos que permita màs mulheres regularizar seu status migratório. Tarapacá

Palavras-chave: Zona Franca, migrações, feminização, emprego, região de

$* * *$

\section{Introducción}

La migración en Chile ha tenido un aumento sostenido durante las últimas décadas (Tapia, 2017). Lo anterior, según la revisión de datos obtenidos del Censo 2017 donde se aprecia que actualmente la población extranjera representa un 4,3\% a nivel nacional, cifra que en el año 1992 solo ascendía a un 0,8\% (INE, 2018).

Este aumento se debe, entre algunos factores, a la influencia de los procesos de globalización, que a partir de la década del 90 implica un contexto de apertura económica sostenida (Sassen, 2003: Stefoni, 2014; GarcíaPizón, 2015); el impacto de los procesos de integración regional (Ramos y Ovando, 2016); la fuerte influencia del modelo económico en el imaginario migratorio de Tarapacá (Amillhat, Szary 2016), etc. Estos acontecimientos han generado movimientos masivos de población en búsqueda de nuevas oportunidades, ya sea en el ámbito laboral, social, psicológico, o para futuros proyectos de vida (Tapia, 2012; Stang y Stefoni, 2017)

En Tarapacá los movimientos de población se registran incluso antes que la región formara parte del territorio chileno ${ }^{1}$. Lo anterior, da cuenta que el proceso migratorio nunca ha dejado de manifestarse y perdura hasta el día de hoy. Así, en la actualidad podemos observar que Tarapacá, según el último Censo de población (2017), es la región que concentra la mayor cantidad de extranjeros en el país, con un 13,7\% (INE, 2018). A pesar que 
este número ha tenido fluctuaciones, es importante considerar que se ha mantenido a través el tiempo. Marcela Tapia (2012b) argumenta que en los siglos XIX-XX, estos movimientos migratorios se vinculan y/o relacionan con la formación de oportunidades de empleos mediante los diversos procesos extractivistas que ha experimentado la región. Sin embargo, a partir de la década de los 90, siendo un factor determinante para este estudio, se produjo un cambio en la composición de las migraciones por género a nivel mundial $^{2}$ (Mora, 2008), cuestión que también impacto en la movilidad fronteriza en el norte de Chile (Tapia y Ramos, 2013). De este modo, Tarapacá se ve representado frente al fenómeno de la feminización de las migraciones (Tapia, 2011), lo que a su vez, trae consigo ciertas novedades en su inserción laboral. Este cambio se comienza a observar en base al creciente ingreso de mujeres autónomas, es decir, sin la necesidad de un acompañamiento por parte de una persona del género opuesto (Stefoni, 2002; Martínez, 2003; Godoy, 2007; Tapia, 2012b). Sin embargo, algunos estudios dan cuenta que su inserción laboral es principalmente en empleos de baja calificación, vinculados a labores de servicios domésticos, industrias textiles, cuidados, agricultura, etc. (Núñez y Stefoni, 2004; Leiva et al., 2017; Stang, 2016; Ramos, 2018)

Por otro lado, en términos geográficos y económicos, este espacio se encuentra influenciado por la contigüidad con otros territorios nacionales (Perú y Bolivia), conformando vías de acceso, tanto para el comercio como para la migración circular ${ }^{3}$ (Mora, 2008; Tapia et al, 2017). Lo anterior, es producto de una convivencia histórica común que precede a la formación de los respectivos Estados-naciones (González y Rouvière, 2008). En este contexto de movilidad humana, verificamos que Tarapacá proyecta su crecimiento económico teniendo como uno de los sectores impulsores en su desarrollo a la Zona Franca de Iquique ${ }^{4}$ (OLT, 2018). Este mecanismo económico regional es una industria que conforma: “el área de extraterritorialidad aduanera, y significó para la región un fuerte impulso al comercio exterior de esta zona. Así como una apertura al turismo nacional e internacional” (Podestá, 2004, p.6). De este modo, se promueve un modelo económico para la región de Tarapacá que pretende producir nuevas oportunidades de empleabilidad y aportar al desarrollo de este territorio fronterizo (González, 1992; Ramos y Ovando, 2016). Sin embargo, los hechos demuestran que las oportunidades de empleabilidad se contrarrestan con una oferta de empleo de tipo precarizado en la Zona Franca de Iquique, y que impacta en las condiciones laborales de un número de trabajadoras que se dedican principalmente a realizar orden y selección de ropa ${ }^{5}$ en un sector específico de Zona Franca, identificado como “Barrio Industrial”.

En suma, tomando en cuenta el aumento de población inmigrante, el contexto fronterizo y la feminización de las migraciones, sumado a los sectores ofertados en el mercado laboral regional y, particularmente la desregulación del empleo en Zona Franca de Barrio Industrial, se conjetura una inserción laboral de mujeres migrantes en condiciones precarias en Zona Franca de Iquique. Lo anterior, determina que un número creciente de mujeres migrantes de países fronterizos se vean expuestas a condiciones 
laborales estructurales de empleo precarizado, lo que finalmente impacta en la producción de irregularidad en su estatus administrativo.

La metodología utilizada en este estudio fue cualitativa. La principal técnica de recogida de información fue entrevistas en profundidad a mujeres migrantes que se encuentran cumpliendo funciones laborales en sector Barrio Industrial de Zona Franca. También se realizaron entrevistas semiestructuradas a representantes gubernamentales que fiscalizan y normalizan las políticas laborales en Tarapacá y a representantes del Sindicato de Trabajadores/as de Zona Franca.

\section{El itinerario de este trabajo es el siguiente:}

En una primera parte, se dará cuenta de algunas características relevantes del contexto de estudio. Así como también describiremos el fenómeno migratorio desde una perspectiva nacional y local. En una segunda parte, se realizará una aproximación teórica respecto a la dimensión del trabajo decente/indecente y el impacto en los flujos migratorios actuales. Seguidamente, se interpretará lo anterior expuesto en base a una serie de entrevistas realizadas en el contexto de barrio industrial de Zona Franca de Iquique. Finalmente, se expondrán las principales conclusiones de este estudio

\section{Tarapacá como zona de estudio}

La región de Tarapacá es hoy en día una de las 16 regiones que forma parte de la división político-administrativa de Chile. Limita al norte con la región de Arica y Parinacota, al sur con la región de Antofagasta, al este con el Estado Plurinacional de Bolivia y al oeste con el océano Pacífico. La región está compuesta por las provincias de El Tamarugal e Iquique y la capital regional es la ciudad de Iquique.

En el ámbito marítimo, por ejemplo, Tarapacá tiene una destacada proyección que la vincula al mercado del Asia Pacífico, considerada una puerta de entrada para el mercado del Centro Oeste sudamericano (Centro Oeste de Bolivia, Paraguay, Norte de Argentina y Brasil). En síntesis, se trató de aplicar en el ámbito local "nuevas reglas económicas, que dejan a cada parte del país libre de valorizar sus "ventajas comparativas" en los mercados mundiales” (AmillhatSzary, 1997, p.59). Para el caso tarapaqueño, se generó un proceso que promovió la inversión extranjera a través de una serie de medidas como fue decretar la Zona Franca para Tarapacá (González, 1992).

En cuanto a su dinamismo económico, identificamos que Tarapacá es un espacio privilegiado por América del Sur como zona de intercambio económico (Ovando, 2012; Tapia y Chacón, 2016), constituyéndose en una zona de intercambio sostenido de bienes, capitales y de tránsito de personas presentes en la subregión andina (Ramos, 2018). En este contexto, en el año 1975 se crea la Zona Franca de Iquique como principal instrumento de 
desarrollo y reactivación de actividades productivas y de servicios regionales. Su objetivo fue impulsar el desarrollo de la primera región que en ese momento atravesaba una crisis económica ocasionada por la inestabilidad de la industria pesquera y la imposibilidad de reflotar el salitre como fuente de divisas para la primera zona del país ${ }^{6}$ (González, 2002 a ).

Un momento significativo que también se registra a partir de los años 90, combinado con estos atractivos económicos y que ha desatado la "preocupación” pública, es la intensa movilidad fronteriza entre Tarapacá y el sureste boliviano, provocando un creciente interés investigativo por revelarlo (Tapia, 2015; Ramos y Ovando, 2016). Este momento significativo se debe, dentro de algunos factores, a la incorporación al mercado mundial a través de la creación de $\mathrm{ZOFRI}^{7}$ en el territorio tarapaqueño; el fuerte impulso de la actividad minera en la región en las últimas décadas y el impacto de los procesos de integración económica regional, como el impulsado por el Mercado Común Regional. Estos acontecimientos han dado lugar a un intenso movimiento de personas y mercancías en el espacio fronterizo del extremo norte chileno (Tapia, 2012; Ramos y Ovando, 2016; Aedo, 2017).

\section{Feminización de las migraciones en el contexto tarapaqueño}

Debido a estos factores de contexto, durante la última década, la región de Tarapacá se ha convertido en un destino privilegiado para mujeres migrantes. Se trata de migrantes laborales del Cono Sur, que trabajaban en países del hemisferio norte y, en menor escala están optando por trasladarse a países como Chile por la particularidad señalada de las regiones como Tarapacá (Tapia, 2012). Esta situación responde, en alguna medida, a que la migración de América Latina se ha visto diversificada sobre todo en años recientes. Por un lado, observamos cómo el contexto de restricciones y crisis económicas de los países del hemisferio norte influye en las decisiones al momento de emigrar (Stefoni, 2002; Tapia y Ramos, 2013) y, por otro lado, vemos cómo esta diversificación se materializa debido a los procesos de integración económica de la región latinoamericana que han llevado a cabo la mayoría de los países en las últimas décadas (CAN; CLARICOM; ALBA; MERCOSUR; GELAC; etc.), y que han permitido -alguno con mayor éxito que otro- que la movilidad de bienes y personas sea más dinámica debido a la existencia de una historia compartida de relaciones económicas y sociales (Nicolao, 2011).

Sin embargo, la inserción laboral de mujeres migrantes trae aparejada diversos procesos de precariedad social y económica. Al respecto Anderson (2006) señala que ha quedado en evidencia que las condiciones de vida de las mujeres migrantes son de una mayor vulnerabilidad respecto a sus condiciones laborales, en trabajos que el autor denomina "las tres p", que quiere decir más penosos, más peligrosos y más precarios. Siendo las muje- 
res migrantes un grupo especialmente vulnerable que sufren la llamada “triple discriminación” por parte de las sociedades receptoras (Parella, 2003). Son discriminadas por su condición étnica, contexto de pobreza, por su situación legal, por ser carentes de redes de apoyo que les otorguen ayuda en su proceso de incorporación social y movilidad transfronteriza (Stefoni, 2014; Stang, 2016).

En este contexto de feminización de las migraciones, y su creciente aumento, se ha logrado estimar que la mitad de los movimientos migratorios son de mujeres (Mora, 2008). No obstante, la tendencia ha sido considerar al migrante en masculino, desatendiendo las características propias de la población femenina y de los problemas que la afectan (Martínez, 2003). Consecuencia de lo anteriormente expuesto, es que se invisibilizan algunas dimensiones de gran interés para comprender la problemática y aportar en el diseño de políticas públicas (Gavilán y Tapia, 2005). De este modo, a pesar que el elemento definitorio de la feminización alude a una participación creciente de mujeres en los flujos migratorios actuales, ésta tiene un impacto cualitativo aún más relevante (Ramos y Urbina, 2012). Lo anterior, dice relación con transformar los significados y consecuencias de la migración internacional que no ha considerado el género en los procesos y políticas migratorias, lo que podría generar potencialidades emancipadoras para muchas mujeres, cuya materialización debe ser objeto de buenas prácticas que deben explorarse en cada caso (Martínez, 2007). Al respecto Reeves (2005) señala que, "si las mujeres y los hombres han de beneficiarse del potencial habilitador y de desarrollo de la migración, se requiere un giro hacia un enfoque de migración basado en el género y los derechos humanos”.(p.10). Esto, dada la disminuida inserción de la mujer inmigrante en cuanto a condiciones óptimas de bienestar, o incluso el acceso a servicios de tipo básico que cualquier ser humano en un Estado de Derecho debiese obtener.

Actualmente la feminización de las migraciones, específicamente de mujeres de origen fronterizo hacia la región de Tarapacá, es un fenómeno progresivo que se ha acentuado en las últimas décadas (Tapia y Ramos, 2013; Leiva, et al., 2017). Esta constatación ha supuesto que las mujeres migrantes asuman el rol de la provisión económica en sus núcleos familiares de manera visibilizada. Sin embargo, es sólo la visibilización de la asunción de la provisión económica por parte de las migrantes, ya que por mucho tiempo han sido proveedoras principales o co-proveedoras de sus familias, inclusive antes de migrar (Tapia, 2011). De este modo, creemos que es relevante considerar el género en los estudios sobre movilidad humana y mercado laboral, considerando que "los enfoques y teorías de las migraciones han dado respuestas parciales tanto a la comprensión de la experiencia migratoria femenina como a la vivencia masculina y la interrelación entre ambos" (Tapia, 2011, p. 123). De esta forma, la perspectiva de género es una clave en la interpretación de la sociedad que pretende discernir y denunciar los condicionamientos culturales que oprimen a la mujer, y a su vez que promueve iniciativas para liberarla de esos condicionamientos (Stang, 2016). 
No obstante, también reconocemos que una perspectiva de género para abordar la inserción laboral de mujeres migrantes fronterizas en Tarapacá, puede resultar limitada dado que existes factores interseccionales - como la clase, raza o etnicidad- que impactan en las condiciones materiales y simbólicas de su inserción en las sociedades de destino ( Magliano, 2015). Así, verificamos a través de algunos estudios que han abordado la cuestión de la interseccionalidad en el fenómeno migratorio, propuestas de un enfoque -aunque no acabo - integral para considerar estos factores interseccionales como procesos dinámicos siempre situados en contextos específicos (Parella, 2003; Anderson, 2006; Mallimaci, 2013).

\section{El mercado del trabajo en Chile: algunas reflexiones de su alcance}

Las diversificaciones en el mercado laboral hacen necesario analizar las estructuras ocupacionales, utilizando como herramienta conceptual la noción calidad de empleo (Galleguillos, 2013). A efecto de este estudio, el concepto de calidad del empleo implicará un acercamiento comprehensivo y holístico de lo que es el mercado laboral, considerando los distintos aspectos del trabajo (Sehnbruch, 2004). De este modo, se reconoce que para estudiar la herramienta conceptual, es importante involucrar el registro de las tasas de empleo y desempleo, crecimiento económico, entre otros aspectos. No obstante lo anterior, este concepto también involucra elementos de suma importancia. Galleguillos (2013) relaciona las oportunidades laborales con la estabilidad de los hogares. Es decir, la calidad de empleo no solo se vincula con el salario, sino que también, con la necesidad de ofrecer trabajos con prestación de beneficios sociales, y de este modo otorgar el bienestar individual y colectivo de los y las trabajadoras.

Lo anteriormente señalado es reconocido por la entidad reguladora internacional (OIT), la cual emplea el término Trabajo Decente, como la capacidad de promoción de los derechos fundamentales. Esto se traduce en considerar diversas dimensiones de análisis, referida principalmente al diálogo social; empleo en cualquiera de sus tipos (formal, informal, dependiente, independiente); los ingresos (cuantía y seguridad) y la protección social(OIT, 1999) ${ }^{8}$. Esta definición generó una base para el lanzamiento del Manual de Trabajo Decente, definiendo las características para un trabajo digno. Esta postura fue generada por medio de las exigencias sociales en vías de una protección hacia los trabajadores y trabajadoras. Exigencias referidas a temas como la igualdad de género, las remuneraciones, la seguridad laboral y estructural, entre otros derechos fundamentales ${ }^{9}$. Sin embargo, existen ciertas limitaciones para reconocer la calidad del empleo y un trabajo decente, debido a que, si bien existen documentos que contienen normativas laborales, como el Manual del Trabajo decente, se generan dos condiciones a la hora de calificar la calidad. Una de aquellas es la satisfacción laboral percibida a través del clima o ambiente y la cultura organizacional y la segunda limitación se refiere a la oferta y demanda laboral, denominada 
“segmentación laboral” (Posso, 2010). En ellas, se propone analizar la calidad de empleabilidad dependiendo de los beneficios adquiridos en el lugar de trabajo. Con ello, al hablar de calidad del empleo se debe considerar la segmentación del mercado laboral con un sector primario restringido, y uno secundario de mayor tamaño, pero con precarias condiciones laborales. Es este último el que mantendría deficiencias en la calidad o en la oferta de oportunidades para sus trabajadores y trabajadoras (Posso, 2010).

En cuanto al estado del mercado laboral en Chile, en términos generales, según el Instituto Nacional de Estadísticas (2018, p. 6), prácticamente uno de cada tres trabajadores asalariados se encuentran en el mercado laboral informal en el año 2017. Es decir, que un 30\% de los trabajadores/as no cuenta con acceso a seguridad social. En el ámbito regional, Tarapacá se ubica por sobre la media nacional respecto a empleados/as informales, con un $37 \%$ del total de la fuerza del trabajo y es la tercera región con mayor empleo en este sector, después de Los Ríos y La Araucanía (INE, 2018). En cuanto a las brechas de género, la tasa de participación femenina nacional, durante el año 2017, se situó en un 48,5\%, mientras que los hombres se ubican en un $71,2 \%$. Sin embargo, verificamos que la tasa de ocupación informal femenina es mayor que la de hombres, con un 31,9\%, mientras que la tasa masculina se ubicó en un 28,6\%. Es importante considerar que 4 de cada 10 mujeres inactivas, señalan que es por razones familiares permanentes. Finalmente, en términos de salarios, el panorama da cuenta que las mujeres perciben menores ingresos que los hombres. Según la Encuesta Suplementaria de Ingresos, las mujeres ocupadas perciben un ingreso medio mensual 31,7\% menor que el de los hombres (ESI, 2016,p. 29). En suma, de acuerdo a estas cifras, podemos verificar que el mercado laboral en Chile, en términos estructurales, se encuentra condicionado por un preocupante porcentaje de personas en el sector informal, siendo Tarapacá la tercera región que concentra la mayor cantidad de trabajadores/as en sector informal. Asimismo, en términos de brechas de género, la situación preocupante se agudiza. Lo anterior, considerando la tasa de ocupación informal, las brechas asociadas al salario y la razón mediante el cual las mujeres están inactivas, da cuenta de actividades asociadas al cuidado permanente.

Por otra parte, respecto a la dimensión “empleo informal”, según la Organización Internacional del Trabajo (OIT) es un tipo de empleo en el que no se respetan los derechos básicos laborales, como por ejemplo, el no uso del trabajo forzoso, la no discriminación y las libertades de asociación y de negociación (OIT, 1997).

En 1991, la 78va reunión de la Conferencia Internacional del Trabajo examinó el dilema del sector denominado "no estructurado". El dilema que se planteaba era si la OIT y sus mandantes, debían promover el sector informal como proveedor de empleo de ingresos, o tratar la informalidad mediante su reglamentación y la protección social. Esto, con la posibilidad de que se redujera su capacidad de proporcionar empleos e ingresos a una mano de obra siempre en aumento, de tal manera de erradicar paulatinamente las peores formas de explotación y de trabajo infrahumana que se obser- 
van en ese sector ${ }^{10}$ (OIT, 2003). Así las cosas, podemos observar que la OIT en su definición más actual del sector informal, incluye a los trabajadores y las trabajadoras, propietarios/as de microempresas, del servicio doméstico, trabajadores familiares no remunerados, agregando como última categoría a los trabajadores/as asalariados que no cuentan con protección social, independiente si están en grandes, medianas o pequeñas empresas, para obtener lo que se ha llamado "la economía o sector informal” (Tokman, 2004).

En cuanto a la economía chilena, a pesar de los avances logrados en materia de crecimiento, inflación, salarios reales, empleo y tasa de desocupación durante los últimos quince años, en el plano social los resultados han sido mixtos. En particular, el escenario de estabilidad macroeconómica, en conjunto con políticas sociales específicas, ha permitido avances significativos en los índices de pobreza y de otros indicadores sociales durante este periodo. Sin embargo, estos avances no se han visto acompañados por mejoras en la distribución del ingreso (Coloma y Rojas, 2000).

Actualmente, el Estado solo se encarga de reconocer un sueldo mínimo el que debe ser respetado por el sector privado (Goncalves, 2010). A partir de lo anterior, se considera que las y los asalariados tienen un empleo informal si su relación de trabajo, de derecho o de hecho, no está sujeta a la legislación laboral nacional, al impuesto sobre la renta, a la protección social o a determinadas prestaciones relacionadas con el empleo (Neffa et al., 2008).

En este sentido, si bien en Chile se ha avanzado en el mejoramiento y actualización de instrumentos de fiscalización, en legislación laboral y en mecanismos de protección pertinentes al nuevo escenario socioeconómico; persisten espacios donde los derechos laborales se ven vulnerados (Gomez, 2010). Con lo anterior, nos referimos a la inestabilidad y precariedad laboral (temporalidad y falta de contratos), incumplimiento de derechos laborales (no pago previsional, acciones antisindicales, etc.), baja sindicalización y capacidad de negociación colectiva, baja participación femenina y juvenil, trabajadores con bajos ingresos, niveles variables de protección frente al desempleo (indemnizaciones y seguro de cesantía), y dificultades para el diálogo social. Con sólo la falta o incumplimiento de alguno de los elementos mencionados, se clasificará el trabajo como informal ${ }^{11}$.

\section{La Zona Franca de Iquique ¿promotor del desarrollo o profundización del empleo informal?}

En una primera aproximación al contexto de estudio, hemos advertido la generación de estrategias migratorias circulares. La migración circular es reconocida con una práctica en contextos de frontera. En ese ámbito, Tapia y Ramos (2013) advierten, que se relaciona con la potencialidad laboral de las zonas fronterizas, y con las posibilidades de mantener conexiones con las comunidades de origen (Leiva et.al, 2017). Lo anterior, se logra desprender de los siguientes relatos: 
Yo al principió comencé trabajando en Arica, por semanas sí. Entraba el lunes hasta el sábado al medio día, y me iba, y después el lunes volvía de nuevo. Así fui llegando poco a poco y fui avanzando así hasta Iquique, en vez de devolverme para allá, me vine más para acá. (Mujer de nacionalidad peruana, seleccionadora de ropa americana en Barrio Industrial- Zofri).

Es reconocida esta práctica laboral circulatoria, siendo una población que cruza la frontera con motivos principalmente económicos, pero sin mayor interés por el asentamiento definitivo (Ramos y Urbina, 2012). Más bien, implica periodos cortos lo que permite a los migrantes transfronterizos realizar viajes de "ida y vuelta" y no interrumpir lazos- culturales y familiares- en sus comunidades de origen. Para estos casos de movilidad temporal, se construyen imaginarios fronterizos que identifican unos límites de Estado territorializado, “alternando la condición objetiva y subjetiva entre el ciudadano y el extranjero, pero en un breve desplazamiento entre cada Estado nación” (Alburquerque, 2004, p. 187). Estos desplazamientos breves se propician, principalmente, por la facilidad que otorgan los medios de transportes, la mejora de las carreteras y la cercanía territorial fronteriza:

Mi hermana chica viene, pero hasta Arica no más, esa (hermana) se va todos los fines de semana, se viene y se va. Pero yo le digo: "pues ya hace tus papeles acá, (sic) están dando una visa que sirve para trabajar" (hermana responde) "No hermanita, me dice, porque tú ya te acostumbraste, yo prefiero mi país, vengo a ganarme un poco de monedas...”. No quiere nada, aparte de eso, ella cruza a Chile solo por ámbitos de trabajo, viene y se va, viene y se va y nada más. (Mujer de nacionalidad peruana, seleccionadora de ropa americana en Barrio Industrial- Zofri).

Las interacciones entre los diversos actores que habitan y circulan en espacios fronterizos, construyen una realidad histórica, y aunque en ocasiones se ha visto afectada por altos y bajos debido a auges o crisis económicas, ha sido una constante en el tiempo. Esta aseveración se funda en que la franja fronteriza tarapaqueña, al igual que toda frontera compartida por dos o más nacionalidades, ve circular, "personas, bienes y significados cuya dirección, intensidad y sentido varían según las épocas, las estaciones, los cambios de moneda, los regímenes aduaneros, las políticas comerciales de los países que convergen en ella” (Giménez, 2011, p. 8), entre otras configuraciones.

Llegué hace cinco años... me vine como de paseo, y acá encontré trabajo. Primero me vine a Santiago por un mes, después me regrese a Bolivia y después de vuelta me regrese pa’ acá (Iquique)... El jefe de donde yo trabajé en Bolivia nos motivó a venir para acá, yo pedía descanso de un mes o dos meses, y después regresaba de vuelta a trabajar. (Mujer de nacionalidad boliviana, seleccionadora de ropa americana en Barrio Industrial- Zofri). 
Los movimientos migratorios en la actualidad, tienen unos rasgos que como fenómeno social lo caracterizan y lo diferencian de oleadas anteriores, como son el incremento y la ampliación de los movimientos transnacionales, la feminización de las migraciones, y junto a ello, la temporalidad en el traslado. Sin embargo, estas condiciones estructurales, en tanto potencialidad de las zonas fronterizas que posibilitan estrategias de migración circular como mecanismo de trabajo, en ocasiones, se ven afectados por las condiciones laborales que ofertan los países receptores.

En este contexto, estudios recientes han abordado las condiciones laborales altamente precarias de trabajadores fronterizos (Leiva tal, 2017), centrando la discusión en recomendaciones para la institucionalidad que permita considerar esta estrategia de empleo, como una forma particular de dinámicas laborales fronterizas. Así, estudios sobre migraciones y trabajo, permiten visibilizar cómo la intersección de clasificaciones sociales (re)produce formas de explotación laboral que se traducen en desigualdades sociales (Magliano, 2015).

Por otra parte, respecto a la dimensión de género asociada al empleo en Barrio Industrial de Zona Franca Iquique, según lo apreciado en el trabajo de campo, ésta no se considera a la hora de ofertar empleo en un rubro que es altamente feminizado. Así como también, no existe la posibilidad de integrar en las dinámicas de empleo, mecanismos que protejan a las mujeres y que permitan, por ejemplo, conciliar su vida familiar y laboral. Lo anterior, lo hemos podido advertir en los siguientes relatos:

De pronto en los permisos hay problemas, porque igual como uno tiene sus hijos, uno tiene que ser madre. Tiene que ir al colegio, o los hijos se enferman y a uno no le dan permiso, o cuando tenía que regularizar mi tema de migrante tampoco me daban permiso. Entonces yo encuentro que eso es un abuso, porque uno como madre si o si tiene que ser responsable de sus hijos”“Si, si el jefe es más complicado, no entiende, es como si no tuviera... como si no tuviera mamá o hijos, no entiende. (Mujer de nacionalidad peruana, seleccionadora de ropa americana en Barrio Industrial- Zofri).

Yo sí, insisto en esto yo asociaría más la precarización del trabajo a trabajadores migrantes, que están recién partiendo. Ahora, no obstante eso, la mayoría de los migrantes no denuncia. Esto sucede de manera potencial, en la zona del barrio industrial y principalmente en las mujeres, entonces lo que hemos detectado nosotros, principalmente a partir de los programas y servicios que damos nosotros mismos, quien denuncia muchas veces o quien ayuda son los sindicatos. (Informante clave, Secretaría Regional Ministerial del Trabajo).

La creciente circulación de personas y bienes materiales e inmateriales en Tarapacá, y junto con ello, la presencia de oferta laboral de tipo precarizado para mujeres que ejercen labores de selección de ropa americana, cuestionan - más allá probablemente de lo que nosotros podemos percibir - las 
formas e ideologías que representa el principal impulsor del comercio y trabajo en la región. De este modo, las mujeres migrantes fronterizas proporcionan recursos esenciales para que se desarrolle el capital en Barrio Industrial de la Zona Franca Iquique. Lo anterior, es una tendencia que permite a las migraciones ajustarse muy bien a los requisitos que impone la flexibilización del trabajo (Sassen 1991), lo que genera como consecuencia acceso a empleo de bajo salario y con condiciones laborales de tipo precarias (Stefoni, 2009):

Sí, igual, usted sabe que no es igual venirse a un lugar donde uno no conoce tanto las leyes, ni de pronto conoce las costumbres, igual es duro... a ver, como le explico. Yo sé que sí, a pesar de que de pronto uno diga que no, pero a veces pasa que abusan de uno... sí, abusan de uno, de pronto porque no sabe, no se ha actualizado con las leyes, con lo que uno tiene que hacer. (Mujer de nacionalidad peruana, seleccionadora de ropa americana en Barrio Industrial- Zofri).

$\mathrm{Si}$, renunciaron, renunciaron porque dicen que ya no están para aguantar a este viejo, yo prefiero a mi hijo, así que yo me voy, no importa, trabajo nunca va a faltar para mi dicen, y se van, renuncian porque no hay permiso para nada. (Mujer de nacionalidad boliviana, seleccionadora de ropa americana en Barrio Industrial- Zofri).

Según los relatos, verificamos que las mujeres migrantes fronterizas que se insertan en el mercado laboral regional, con la finalidad de mejorar sus condiciones económicas, no son únicamente condenadas a ocupar los márgenes de las sociedades, o los espacios subterráneos en palabras de Tarrius (2001). Sino que también, su ámbito de acción se anula cuando operan las lógicas de una legislación laboral que no se encarga de supervisar las diversas vulneraciones de derechos de la cual las mujeres migrantes son expuestas. En este escenario, se hace necesario incorporar una comprensión laboral subordinada de las mujeres migrantes trabajadoras, considerando la complicidad que presentan los ejes del género, la clase y la raza en un contexto de producción capitalista que genera procesos de marginación y explotación laboral (Parella, 2005). Así, se identifica a través de los discursos que desconocer los derechos laborales, es un caldo de cultivo para el abuso por parte de las y los empleadores, anulando la posibilidad de reclamo, ya sea por desconocimiento o miedo a ser denunciadas. Estas expresiones de exposición y vulnerabilidad, desde una lógica de la era soberana, son reservados para los “nadies” (Giráldez, 2016). Su presencia se deniega en los espacios e instituciones públicas, invisibilizado socialmente lo que representan y perpetuando las desigualdades estructurales construidas a partir de la invisibilización de las variables asociadas al género, la clase o la raza. Aquella triple discriminación que nos advierte Parella (2013), sostiene un incremento real de las prácticas coercitivas y de discriminación, lo que a su vez incita un racismo desmesurado. Lo anterior lo apreciamos en los siguientes relatos: 
Por la dificultad, por todo poh, porque a veces por el color de piel y algunos si son chilenos, que son recriminadores también. Me decían india, paisana, pero yo no le tomaba importancia, igual no más yo le decía:”dime todo lo que querai, porque tú no me mantienes a mí, no das ni un pan para mí”. Le dije yo así, entonces no... no le hacía casos no más. A veces digo, pucha para qué vine para acá, en vez de regresarme de Arica para Tacna y me vine hasta Iquique, mejor me hubiese ido pa’ allá pa’ mi país. (Mujer de nacionalidad peruana, seleccionadora de ropa americana en Barrio Industrial- Zofri).

Dentro del recinto amurallado los inmigrantes son mucho más... más necesitados que los propios chilenos, hay una discriminación dentro de ese recinto, que siempre contratan mucho más inmigrantes, que gente nacida acá. (Informante clave. Sindicato de Trabajadores/ as- Zona Franca Iquique).

Este racismo es un efecto que provoca fragmentar la población que se encuentra dominada por el biopoder (Foucault, 2006). Una exposición que se desarrolla en el marco de indefensión generada por las políticas públicas laborales. Así como también, generadas por los obstáculos legales en la obtención de permisos laborales para personas en permanente movimiento, como es el caso de la ley de extranjería actualmente vigente. ${ }^{12}$

Lo anterior, genera una paradoja en las dinámicas laborales. Por un lado, el Estado chileno y su economía desterritorializada necesitan la fuerza laboral de mujeresmigrantes en condiciones precarias, pero potencialmente productiva (considerada siempre como fuerza productiva de bajo valor). Por otro lado, la carga de su cuerpo provoca que el Estado se reterritorialice en virtud de sus sesgos de control:

El inmigrante es un viviente puesto en juego a la intemperie de la excepcionalidad neoliberal. A fin de cuentas, en lo que se refiere a su relación jurídica con el Estado, usualmente al inmigrante el derecho no lo protege, pero sí lo persigue. (Tijoux y Díaz, 2014, p.304).

Así, podemos observar a través de los relatos, que la oferta laboral se predispone únicamente a la variable productiva de la mujer pero cuando,por ejemplo, necesitan realizar gestiones administrativas que le permitan ser sujetas de derecho, el empleador se niega a otorgar permisos necesarios. Lo anterior, se logra desprender de los siguientes extractos:

No te dan permiso, el jefe pone caracho (mala cara), si usted quiere hacer los papeles, mejor deje el trabajo, y no trabaje.(Mujer de nacionalidad peruana, seleccionadora de ropa americana en Barrio Industrial-Zofri).

Les da lo mismo a los usuarios (la situación migratoria)... mucho de los usuarios tienen mucha gente sin contrato, como les he contado. 
(Informante clave. Sindicato de Trabajadores/as de Zona Franca Iquique)

$\mathrm{Si}$, cuando pido permiso seguido casi, y me dice, porque... como dije anteriormente, porque si usted los tramites entonces retírese, no trabaje. (Mujer de nacionalidad peruana, seleccionadora de ropa americana en Barrio Industrial- Zofri).

lamentablemente el empleo precario es la manera ... se asocia al trabajador extranjero que trabaja por lo que sea, en las condiciones que sea, he ... el empleo precario por ejemplo es el caso de los trabajadores migrantes que estando de manera irregular, en materia de permisos por ejemplo, he ... se filtra para ellos, el empleo precario sin duda afecta hoy en día a los trabajadores extranjeros, porque son trabajadores que no tienen contrato, porque a lo mejor todavía no están regularizados, son aquellos que además por la razón que están acá. (Informante clave. Secretaria Regional Ministerial del Trabajo).

En el ámbito de las lógicas materiales, la posibilidad de regularización migratoria, que permite acceso a derechos, queda condicionada por la configuración del espacio que ordena el Estado (Ramos, 2018). Estas posibilidades se apoyan en lo jurídico, en tanto que su materialidad dispone de un marco normativo que define lo social, así como también definirá la forma en que esa posibilidad puede quedar expuesta a los mecanismos laborales, mediante el cual, "las mujeres trabajadoras se sitúan así en los estratos más bajos de la estructura ocupacional, en aquellas actividades más precarizadas, menos remuneradas y menos valoradas socialmente" (Parella, 2000, p. 280).Lo anterior, lo hemos advertido en los relatos de las entrevistas realizadas al Director del Trabajo y la Presidenta del Sindicato de Trabajadores de Zona Franca:

Fuera del recinto amurallado [barrio industrial] se han detectado alrededor de 20 empresas, eh... clasificadoras y seleccionadoras de ropa, eh... que es una realidad que nosotros hemos podido detectar y que es bastante más complicada para los trabajadores. Es más, hemos encontrado más informalidad, hemos encontrado precarización, no hemos encontrado con problemas con jornadas fuera del recinto, eso lo hemos detectado. (Informante clave, Secretaria Regional Ministerial del Trabajo)

$\mathrm{Si}$, ellos [dirección del trabajo] tienen todo el conocimiento que dentro del recinto se vulneran derechos, pero como el recinto es tan grande, a veces tampoco da a los fiscalizadores para fiscalizar toda la ZOFRI.(Informante clave. Sindicato de Trabajadores/as de Zona Franca Iquique).

En el ámbito de lo simbólico, por su parte, el Estado gestionará las ausencias necesarias para invisibilizar las subjetividades que encarna a un sujeto fronterizo, que en último término se define más por lo que son (por la 
carga simbólica o perfil del sujeto expuesto) que por lo que ha hecho. Finalmente se conjugan los poderes económicos propios del neoliberalismo, permitiendo mercantilizar y financiar los modos de existencia (Mendiola, 2017). De este modo, observamos cómo la expansión de la economía informal permite reducir los costes de producción, favoreciendo la flexibilización y la desregulación de la fuerza de trabajo y creando condiciones para la absorción de mano de obra femenina y extranjera (Sassen, 2003)

Así, queda expuesta la paradoja del Estado. Por una parte, “deja vivir" a individuos y grupos en la condición de discriminados que sirven como mano de obra del trabajo precario -gestionando de paso el ilegalismoal dejar proliferar la mano de obra barata del condenado a la figura de inmigrante-ilegal. Por otra parte, el racismo de Estado perpetúa las variables estructurales de vulnerabilidad durante la expropiación de sus fuerzas de trabajo en condiciones abiertamente desreguladas, abandonándolos, desprotegiéndolos y finalmente desechando sus cuerpos que ya no sirven (Tijoux y Díaz, 2014).

Esta exposición se manifiesta a través de las diversas prácticas que hemos expuesto en los relatos presentados anteriormente. Así, verificamos la exposición a la ilegalidad en la medida que es negada la posibilidad de regularizar trámites migratorios para la obtención de visados de residencia.

Si, una vez me enfrente con él, porque le iba hacer el trámite a mi hijo, él me dio permiso en la mañana, pero igual, como era en la Gobernación me tomó toda la mañana. Entonces yo me vine a presentar entonces él me dijo :" vienes no más a almorzar señora XXX (insulto)", y yo le dije, "No, solo que, vine porque pues usted me dio permiso, y yo vine a penas me desocuparon allá, ay me dijo, eso sí me lo dijo "de saber que ibas hacer los trámites de su hijo, no le doy el trabajo", pues y allí me sentí como ... como que ... porque eso es discriminación o una forma de hacerlo sentir como menos a uno. (Mujer de nacionalidad boliviana, seleccionadora de ropa americana en Barrio Industrial- Zofri).

No contar con documentos los convierte en sujetos sin una base administrativa, una vida ilegal que permanece abandonada en un turbio umbral entre hecho y derecho que expone sus vidas y subjetividades (Tijoux y Díaz, 2014). Se expone porque los convierte en perfiles de una vida que es despreciada, abandonada, anulada, que se puede sacrificar y explotar según sea el interés del que ejerza el poder sobre esa vida precaria.

He...a veces si, a veces no...pero... nos retan, porque nos dice, aquí no se da permiso, que están leyes, que por eso reciben personas con su definitiva, porque no les gusta que uno esté en situación de trámites y bueno después de todo, uno acata no más. (Mujer de nacionalidad colombiana, seleccionadora de ropa americana en Barrio Industrial- Zofri). 
En lo que son principalmente las clasificadoras de ropa, ahí si se da, hay como 20 empresas donde efectivamente se ha encontrado un trabajo más precario. He... en eso podemos concluir o inferir en definitiva, que los trabajadores extranjeros que llevan poco tiempo, he... tienen empleos más precarios, yo creo que sí. ¿Cuándo se regulariza esto? ¿Cuándo ellos van ganando? por ejemplo ya están de manera regularizada, obviamente ya valoran un poco más. (Informante clave. Secretaria Regional Ministerial del Trabajo).

A partir de estas escenarios de movilidad, los espacios de frontera gestan complejas redes sociales transfronterizas que contribuyen a otorgar posibilidades en la inserción laboral de mujeres migrantes, pero en condiciones precarias y desreguladas. En suma, esta condición nospermitiría establecer una correlación, según la cual, la multiplicación de los obstáculos legales para la inserción formal del empleo mediante la regularización de sus antecedentes migratorios, constituiría un caldo de cultivo para la inserción laboral informal de mujeres migrantes que desarrollan laborales de seleccionadora de ropa en Barrio Industrial de Zona Franca Iquique.

\section{Conclusiones}

Tarapacá como frontera internacional, junto con sus dinámicas económicas y sociales en el marco de la globalización, ha logrado generar una inusitada importancia en torno a tres variables económicas, aquellas que aluden al, "comercio y exportación de bienes primarios, infraestructura y seguridad” (García Pizón, 2015, p. 120). La integración económico-comercial de la zona norte de Chile incide en la promoción de las exportaciones y la vinculación del comercio con la inversión extranjera (Ranfla, 1984). Esta apertura económica, dado el entorno privilegiado de la región, se complementa a nivel nacional con un: "activo bilateralismo que trajo consigo una serie de Tratados de Libre Comercio (TLC) y diversos acuerdos de complementación económica” (Fuentes, 2008, p. 130).Dentro de estos rasgos, uno de los más importantes lo constituye, por su repercusión social y política, la inserción laboral de mujeres migrantes, pudiéndose determinar, a través de la identificación de un alto número de mujeres que trabajan en Zona Franca de Iquique, las dificultades que se encuentran para acceder a derechos laborales y sociales.

En este contexto, actualmente las zonas fronterizas son un potencial de empleo para mujeres migrantes. Lo anterior, dado que la cercanía con el cruce permite seguir manteniendo vínculos con las comunidades de origen. Este potencial emancipador para mujeres, en la práctica, resulta limitado en la medida que no existe una institucionalidad que reconozca la movilidad circulatoria como una dinámica laboral fronteriza. Por el contrario, se generan una serie de restricciones, como hemos podido evidencias a través de los relatos, que dificultan la inserción laboral formal de mujeres migrantes que trabajan en Barrio Industrial.Como por ejemplo, la imposibilidad de mejorar sus condiciones laborales mediante la dificultad de regularizar sus 
trámites de extranjería para la obtención de permisos de empleo que les permita gozar de condiciones laborales más justas. De este modo, hemos observado que la discrecionalidad con la que operan los empleadores a la hora de facilitar un proceso de regularización, junto con las condiciones laborales precarias,exponen a las mujeres migrantes fronterizas a condiciones de vulnerabilidad estructural.

En este complejo escenario fronterizo, consideramos que el reto en el tratamiento que se le otorga a los estudios fronterizos en los espacios que mantienen una fuerte influencia de ofertas de empleo desregulada, es avanzar hacia el desarrollo de investigaciones desde miradas transversales, reconociendo la complejidad que representa el abordaje de la noción de fronteriza y considerarla como una expresión influyente en el territorio que determina, en muchas ocasiones, las formas de inserción laboral para mujeres migrantes fronterizas que se encuentran en permanente movimiento.

\section{Agradecimientos}

Resultado del proyecto de investigación titulado: "percepción de las mujeres migrantes que trabajan en el recinto amurallado de Zofri, respecto a sus condiciones laborales”. Financiado por la Vicerrectoría de Investigación, Innovación y Posgrado de la Universidad Arturo Prat. Decreto Exento $\mathrm{N}^{\circ} 0276-2018$. 


\section{Notas}

${ }^{1}$ En 1883, con el Tratado de Ancón, se dio por finalizada la Guerra del Pacífico, y con ello iniciar el proceso de chilenización del territorio.

${ }^{2}$ Para el año 2000 el 48\% de los 175 millones de migrantes a nivel mundial eran mujeres (UnitedNations, 2002) y, en América Latina, el año 2002 ellas representaban el 50.5\% de los migrantes (Ramírez, García yMíguez, 2005).

${ }^{3}$ Es por estas dinámicas culturales y comerciales que consideramos a la franja fronteriza tarapaqueña como un espacio de amplitud variable, en que convergen dos regiones contiguas, una chilena, Tarapacá, y otra boliviana, Oruro (Giménez, 2009).

${ }^{4}$ El inicio de la Zona Franca de Iquique, tiene como hito principal el DFL $N^{\circ} 6$ del año 1969, firmado por el presidente de ese entonces, señor Eduardo Frei Montalva acompañado del ministro de hacienda señor, Andrés Zaldívar Larraín. Luego de 4 años, específicamente el 25 enero de 1973, y bajo el mandato del presidente Salvador Allende y la superintendencia de sociedades anónimas, dictan la resolución $N^{\circ} 30$ que logra dar vida a la Sociedad Administradora y operadora de Zonas Francas S.A. Dicha Sociedad se constituyó el 26 de febrero de 1990, y el 29 de septiembre del mismo año, entró en vigencia el contrato de concesión en materia de Administración y Explotación de la Zona Franca de Iquique cuya duración se pactó en 40 años.

${ }^{5}$ Esta labor consiste en separar y ordenar por calidad la ropa americana proveniente de otros países que vienen aglutinadas en grandes fardos, la ropa es extraída y agrupada por “ITIS”( se separa la ropa dependiendo de la sección, de deporte, bebés, entre otros),además de la distinción de ropa de primera, segunda y tercera calidad . Cada fardo de ropa pesa según el reglamento aduanero de Chile 42kilos aproximadamente.

${ }^{6}$ La historia de la Zona Franca de Iquique, Diario el Nortino, 11 de diciembre de 2011

${ }^{7}$ En términosestructurales la Zona Franca Iquique es el máximo impulsor de la economía en la región de Tarapacá, aportando más de 20.000 empleos directos e indirectos (OLT, 2018).

${ }^{8}$ Organización Internacional del Trabajo, OIT. Trabajo decente, Memoria del Director General a la $87^{\mathrm{a}}$ reunión de la Conferencia Internacional del Trabajo, Ginebra, 1999.

${ }_{9}^{9}$ Declaración Universal de los Derechos Humanos(1948),el Pacto Internacional sobre Derechos Económicos, Sociales y Culturales(1966), la Declaración Mundial Social Cumbre y sus Compromiso (1995), la Declaración de la OIT sobre Principios Fundamentales y Derechos al Trabajo(1998)

${ }^{10}$ OIT: El dilema del sector no estructurado. Memoria del Director General. Conferencia Internacional del Trabajo, 78va reunión, 1991. Ginebra.

${ }^{11}$ Informalidad laboral: más trabajadores productivos sin protección laboral. Dirección del Trabajo, Gobierno de Chile, diciembre 2015. 
${ }^{12}$ Esta ley refuerza la percepción de la migración como una amenaza para la seguridad del Estado, particularmente en cuanto a su estabilidad política, económica y moral. Diseñada durante la dictadura militar de Pinochet, la Ley de Extranjería de 1975 se construyó sobre la base de la doctrina de la 'seguridad nacional', que ve al extranjero como un enemigo (García Pizón, 2015). 


\section{Bibliografía}

Aedo, A. (2017). Encarnando (in)seguridad. Orden policial y política de la presencia en la frontera norte de Chile. Antípoda. Revista de Antropología y Arqueología (29), 87-103.

Alburquerque, F. (2004). Desarrollo económico local y descentralización en América Latina.Revista de la CEPAL ( $\left.{ }^{\circ} 8\right)$.

AmillhatSzary, A. (1997). Regiones ganadoras y regiones perdedoras en el retorno de la democracia en Chile: poderes locales y desequilibrios territoriales. EURE (70), 59-78.

AmillhatSzary, A. (2016). Gentes y agentes, condiciones paradiplomáticas de la creación de una frontera móvil. Relaciones transfronterizas y paradiplomacia en América Latina: Aspectos teóricos y estudios de casos.Santiago, Chile: Editorial RIL.

Anderson, B. (2006). A very private business: migration and domestic work. WorkingPaper, 28.

Coloma, F y Rojas. P.(2000).Evolución del Mercado Laboral en Chile: Reformas y Resultados. Santiago, Chile: centro de estudios públicos (CEP)

Focault, M. (2006). Seguridad, territorio, población. Curso en el Collège de France (1977-1978). Ciudad de México, México: Fondo de Cultura Económica.

Fuentes, C. (2008). Fronteras calientes. Latinoamérica, 8 (3), 12 - 21

Galleguillos, S. (2013). Sobre la calidad del empleo y la estructura social: una aproximación al estudio de la estructura ocupacional en Chile.Santiago, Chile. Universidad de Chile.

GarcíaPizón, V. (2015). Estado y frontera en el norte de Chile. Revista de Estudios Fronterizos, nueva época, 16, (31), 117-148.

Gavilán, V., y Tapia, M. (2005). Diagnóstico de los procesos migratorios en el norte de Chile. Revista Parinas.

Giménez, G. (2009). Cultura, identidad y memoria: Materiales para una sociología de los procesos culturales en las franjas fronterizas. Frontera Norte, 21(41), 7-32.

Giménez, V. (2011). La “triple frontera” y sus representaciones: Políticos y funcionarios piensan la frontera, Frontera Norte, 23(46), 7-34. 
Giráldez, A. (2016). El dispositivo Frontera: la construcción espacial desde el cuerpo migrante. Acta de congreso. II Internacional conferenceonarchitecturalDesing and Criticism, UPM, , Madrid, España.

Godoy, L (2007).Fenómenos migratorios y género: identidades femeninas”remodeladas”. Psykhe (Santiago), 16(1), 41-51.

Goncalves, R. (2010). Salario mínimos en Chile: ¿Están ciertas personas destinadas a ganar el sueldo mínimo de por vida? Santiago, Chile: Universidad de Chile.

Gómez, S. (2009).La subcontratación en la minería en Chile: elementos teóricos para el análisis. Polis, Revista Latinoamericana8(24), 111131. doi:10.4067/S0718-65682009000300007

González, S. (1992).La zona franca de Iquique y su perspectiva industrial: un dilema regional. Revista EURE18 (54), 79-90.

González, S. (2002a). Violencia en los andes de Tarapacá: una reflexión teórica.Diálogo andino(20/21). Recuperado de: http:// dialogoandino.cl/wp-content/uploads/2016/07/DA-20-21-200102.pdf

González, S., yRouvière, L. (2008). De “Aymaras en la frontera” a “Aymaras sin fronteras”. Los gobiernos locales de la triple-frontera andina (Perú, Bolivia y Chile) y la globalización. Diálogo Andino, (31), 31-46.

INE (2018) Boletín de empleo trimestral. Edición 242. Recuperado de: http://www.ine.cl/docs/default-source/boletines/Empleo/2018/ espa\%C3\%B1ol/bolet\%C3\%ADn-empleo-nacional-trimestrem\%C3\%B3vil-son-2018.pdf?sfvrsn=5

2016) Encuesta Suplementaria de ingresos. Recuperado de: http:/ /www.ine.cl/estadisticas/ingresos-y-gastos/esi

Leiva, S., Mansilla, M y Comelin, A. (2017). Condiciones laborales de migrantes bolivianas que realizan trabajo de cuidado en Iquique. SiSomos Americanos, 17 (1), 11-37

Magliano, M. (2015). Intersectionality and Migrations: Potentialities and Challenges. Revista Estudos Feministas, 23(3), 691-712.

Mallimaci, A (2001). Migraciones y géneros. Formas de narrar los movimientos por parte de migrantes bolivianos/ as en Argentina. Revista Estudos Feministas, 19(3), 751-775

(2013) Localizando el sentido de las desigualdades. Inclusiones y exclusiones de los/as bolivianos/as en Ushuaia. En: G. Karasik. 
Migraciones internacionales.Reflexiones y estudios sobre la movilidad territorialcontemporánea, (pp. 87-106). Buenos Aires, Argentina: CICCUS.

Martínez J. (2003). El encanto de los datos. Sociodemografía de la inmigración según el censo de 2002, Santiago, Chile: CEPAL.

(2007). Feminización de las migraciones en América Latina: discusiones y significados para políticas. ACNUR,

Mora, C. (2008). Globalización, Género y Migraciones. Polis. Revista Latinoamericana, 7(20), 285-297.doi:

Mendiola, I. (2017). De la biopolítica a la necropolítica: la vida expuesta a la Muerte. Eikasia, revista de filosofía, 215-245.

Neffa, J. C., Álvarez, S., Battistuzzi, A., Biaffore, E., y Suárez, A. (2008). La informalidad, la precariedad laboral y el empleo no registrado en la provincia de Buenos Aires. Buenos Aires,Argentina: CEIL-PIETTE, CONICET y Ministerio de Trabajo .

Nicolao, J. (2011). Migraciones intrarregionales en Sudamérica. Boletín Elcano, (134), 10

Núñez, L. y Stefoni, C. (2004).Migrantes andinos en Chile: ¿transnacionales o sobrevivientes? En C. Stefoni. (ed.)Los nuevos escenarios (Inter) nacionalesChile 2003-2004. (pp. 267-287). Santiago, Chile: FLACSO-Chile.

Ovando, C. (2012). La seguridad internacional en la proyección de Chile hacia el Cono Sur: ¿desde la doctrina de la seguridad nacional hacia la construcción de comunidades de seguridad o la emergencia de la securitización?, Revista Bogotá, 7 (2).

Observatorio laboral de Tarapacá (2018). Reporte Sectorial Comercio. Recuperado de: http://oltarapaca.cl/wp-content/uploads/2018/07/Reporte-Sectorial-Comercio.pdf

OIM. (1991).El dilema del sector no estructurado. Memoria del Director General. Conferencia Internacional del Trabajo, 78va reunión, Ginebra.

OIT. (1999) Trabajo decente, Memoria del Director General a la 87ª reunión de la Conferencia Internacional del Trabajo, Ginebra.

Parella, S. (2000). El trasvase de desigualdades de clase y etnia entre mujeres: los servicios de proximidad. Papers: revista de sociologia, (60), 275-289. 
(2003). Mujer, inmigrante y trabajadora: la triple discriminación. Madrid, España:Anthropos Editorial.

(2005). La "vulnerabilidad social” de las mujeres inmigrantes nocomunitarias a partir del estudio de sus pautas de inserción laboral en España. Revista REDSI-Red Social Interactiva, 6.

Podestá, J. (2004). La invención de Tarapacá. Estado y desarrollo regional en Chile. Iquique, Chile:Ediciones Campus:.

Posso, C. (2010). La calidad del empleo desde la perspectiva de la segmentación laboral: Una análisis para el mercado laboral colombiano 2001 - 2006. Desarrollo y Sociedad (65) 191 - 234

Ramírez, C., García, M. y Míguez, J. (2005). Cruzando fronteras. Remesas, género y desarrollo. Instituto Internacional de Investigación y Capacitación de las Naciones Unidas para la Promociónde la Mujer. Recuperado de: http://www.un-instraw.org/en/ i m a g e s / s t o r i e s / r e m m i t a n c e s / d o c u m e n t s / cruzando_fronteras.pdf.

Ramos, R. y Urbina, D. (2012). Percepción de las mujeres inmigrantes usuarias de la Pastoral de Migraciones INCAMIIQUIQUE, en cuanto a su vinculación con las redes de apoyo en la región de Tarapacá. (Tesis inédita)Universidad Arturo Prat, Iquique, Chile.

Ramos, R.y Ovando, R. (2016) La región de Tarapacá: Seguridad fronteriza y múltiples apropiaciones de su espacio. Polis Revista Latinoamericana,15 (44), 57-81.

Ramos, R (2018). Entre poder y resistencias: análisis de las movilidades no-territoriales en la zona fronteriza de la región de Tarapacá. Revista diálogo andino, (57), 83-94. Recuperado de: http://dialogoandino.cl/ wp-content/uploads/2018/12/07-RAMOS-RDA57.pdf

Ranfla, A. (1984). Frontera política y espacio fronterizo. Estudios Fronterizos. 1 (4-5), 47-68.

Reeves, H (2005). Género y migración: Informe general. Brighton, ReinoUnido:University of Sussex

Sassen, S. (1991).The global city. New York, London and Tokyo. Princeton, United States:Princeton University Press).

(2003). Contrageografías de la globalización. Género y ciudadanía en los circuitos transfronterizos. Madrid, España: Traficantes de Sueños.

Sehnbruch, K. (2004). From quantity to the quality of employment.Berkeley, UnitedStates: University of California. 
Stang, F. (2016). De la Doctrina de la Seguridad Nacional a la gobernabilidad migratoria: la idea de seguridad en la normativa migratoria chilena, 1975-2014. Polis Revista Latinoamericana,15(44), 83-107.

Stang, F.y Stefoni, C. (2016). La microfísica de las fronteras. Criminalización, racialización y expulsabilidad de los migrantes colombianos en Antofagasta, Chile.Astrolabio (17), 42-80.

Stefoni, C. (2002). Mujeres inmigrantes peruanas en Chile. Papeles de población, 8(33), 117-144.

(2009) Migración, género y servicio doméstico. Mujeres Peruanas. En M.E.Valenzuela y C. Mora (eds.) Trabajo doméstico en Chile: un largo camino hacia el trabajo decente (pp.191 232).Santiago,Chile: OIT

(2014).Perspectiva transnacional en los estudios migratorios: Revisión del concepto y nuevos alcances para la investigación. En W.Imilan, A. Garcés, y Margarit, D. (eds.). Poblaciones en movimiento: Etnificación de la ciudad, redes e integración.(pp. 41-65). Santiago, Chile: Ediciones Universidad Alberto Hurtado.

Stefoni, C.yStang, F. (2017). La construcción del campo de estudio de las migraciones en Chile: notas de un ejercicio reflexivo y autocrítico. Íconos. Revista de Ciencias Sociales,(58), 109-129.

Tapia, M. (2011). Género y migración: trayectorias investigativas en iberoamérica.Revista Encrucijada Americana, (2) 115-147

(2011b).La migración como escenario para la comprensión de la violencia de género entre migrantes internacionales. Amérique Latine Histoire et Mémoire. Les Cahiers ALHIM. (21). Grenoble.

(2012a). Migración y movilidad de los trabajadores fronterizos en Tarapacá durante el ciclo del nitrato. 1880-1930. En S. González (ed.).La sociedad del salitre: protagonistas, migraciones, cultura urbana y espacios públicos, 1870-1940. Santiago, Chile: RIL Editores.

(2012b). Frontera y migración en el norte de a partir del análisis de los censos población: Siglos XIX-XXI. Revista de geografía Norte Grande, (53), 177-198

Tapia, M. y Ramos, R. (2013). Mujeres migrantes fronterizas en Tarapacá a principios del siglo XXI: El cruce de las fronteras y las redes de apoyo. Polis Revista latinoamericana,12(35), 229-257. doi;10.4067/ S0718-65682013000200011. 
Tapia, M. (2015). Frontera, movilidad y circulación reciente de peruanos y bolivianos en el norte de Chile. Revista de Estudios Atacameños Arqueología y Antropología Surandinas. (5), 195- 201.

Tapia, M y Chacón, F (2016). Vínculos transfronterizos: vida, movilidad y comercio en el barrio boliviano de Iquique, Chile, REMHU - Rev. Interdiscip. Mobil. Hum., (47), 131-152

Tapia, M., Liberona, N. y Contreras, Y. (2017). El surgimiento de un territorio circulatorio en la frontera chileno-peruana: estudio de las prácticas socio-espaciales fronterizas. Geografía Norte Grande(66), 117141

Tijoux, M. y Díaz, L. (2014).Inmigrantes, los “nuevos bárbaros” en la gramática biopolítica de los estados contemporáneos”. RivistaInternazionale di FilosofiaContemporanea ,2 (1)

Tarrius, A. (2000). Leer, describir, interpretar las circulaciones migratorias: conveniencia de la noción de "territorio circulatorio”. Los nuevos hábitos de la identidad. Relaciones, 21 (83), 37-66.

Tokman (2004).Una voz en el camino: empleo y equidad en América Latina, 40 años de búsqueda, Santiago, Chile: Fondo de Cultura Económica 